\title{
Dimensões da hospitalidade em um restaurante comercial
}

\section{Dimensions of hospitality in a commercial restaurant}

\author{
Luciema De Boer (BOER, L. de) ${ }^{*}$ e Mirian Rejowski (REJOWSKI, M.) ${ }^{* *}$
}

\begin{abstract}
RESUMO - Neste artigo se investiga um local público de alimentação fora do lar, com o objetivo de verificar como se estabeleciam as relações e vínculos sociais nesse espaço. Desenvolveu-se um estudo de caso no restaurante Madalosso, localizado em Curitiba (ParanáPR), Brasil, utilizando a análise de documentos, visitas in loco, observação participante e entrevistas semiestruturadas. Como empreendimento familiar e de tradição italiana no estilo de servir e degustar, estava fortalecendo a sua identidade e o seu posicionamento no turismo e lazer. Os resultados constataram: bom atendimento, sentimentos de familiaridade, ausência de cerimônia e formalismo e o uso de regras e rituais. A experiência dos clientes envolvia a própria refeição e suas formas de interação e o contato com os funcionários. A percepção dos entrevistados reforçou a visão positiva do empreendimento como um lugar hospitaleiro em todas as suas dimensões, onde o bom acolhimento estava sendo fator de atração e fidelização do cliente, e a hospitalidade influenciava positivamente a comensalidade aliada à sociabilidade. A pesquisa foi realizada no próprio restaurante, sendo a divulgação da pesquisa sido autorizada formalmente pelos proprietários no período de 2013 a 2015.
\end{abstract}

Palavras-chave: Hospitalidade; Gastronomia italiana; Restaurante comercial; Comensalidade; Sociabilidade.

ABSTRACT - This article investigates a public place of food outside the home, aiming to verify how relations and social ties are established in that space. It develops a case study in Madalosso restaurant, located in Curitiba (PR) using the analysis of documents, site visits, participant observation and semi-structured interviews. It is a family businnes with Italian tradition in the style of serving and tasting, which strengthens and accentuates its identity and its positioning in tourism and recreation. The results found: good service, feelings of familiarity, lack of ceremony and formality, as well as the use of rules and rituals. The customer experience involves the meal itself, its forms of interaction and contact with staff. The perception of respondents reinforced the positive outlook of the enterprise as a hospitable place, where the good reception is factor of attraction and customer loyalty, and it shows that the hospitality positively influences the commensality allied with sociability.

Key words: Hospitality; Italian Gatronomy; Restaurant; Commensality; Sociability.

\footnotetext{
*Formação: Bacharel em Direito pela FMU - Faculdades Metropolitanas Unidas, Graduação em Tecnologia da Gastronomia pela Universidade Anhembi Morumbi, Especialização em Docência em ensino superior com ênfase em gastronomia pelo SENAC e Mestre em Hospitalidade pela Universidade Anhembi Morumbi. Atuação profissional: Professora do curso de Tecnologia em Gastronomia presencial e on-line da Universidade Anhembi Morumbi. Endereço físico para correspondência: Rua Adalívia de Toledo, 325, ap. 81 (Bairro Paineiras do Morumbi). CEP 05683-000 - São Paulo - São Paulo (Brasil). Email: ludeboer@gmail.com

** Formação: Graduação em Turismo, Mestrado e Doutorado em Ciências da Comunicação, e Livre Docência em Teoria do Turismo e do Lazer pela Universidade de São Paulo. Atuação profissional: Professor titular do Mestrado e Doutorado em Hospitalidade e da Graduação em Turismo da Universidade Anhembi Morumbi. Professor Sênior da Universidade de São Paulo na área de Turismo. Endereço físico para correspondência: Avenida Jacutinga, 242, apto. 53 (Bairro Indianópolis). CEP 04515-030 - São Paulo - São Paulo - Brasil. Email: mrejowski@ gmail.com.
} 


\section{INTRODUÇÃO}

A hospitalidade tem como seu ponto fundamental a interação entre as pessoas, na qual se institui uma dinâmica de reciprocidade. Pode ser considerada como um dos alicerces da constituição dos vínculos sociais, uma vez que abre espaços para uma ação interativa entre indivíduos - hóspede e anfitrião - e, dessa forma, proporciona momentos de construção de relações sociais.

Concorda-se com a afirmação de Boutaud (2011) que uma das formas mais conhecidas de hospitalidade, em qualquer época e em todas as culturas, é o compartilhar à mesa ou a refeição com alguém. Ressalta-se como ponto central a alimentação, que para Camargo (2004), pode ser estudada a partir de três perspectivas: a) perspectiva da dietética: em que há a tentativa de criar uma alimentação visando prescrições alimentares sob a ótica da medicina/nutrição para a boa saúde; b) perspectiva da gastronomia: que se ocupa em pensar as combinações que proporcionam o melhor sabor aos alimentos; e c) perspectiva das ciências humanas: com a abordagem da comensalidade, campo indissociável do prazer do alimento com a satisfação da companhia no ato da alimentação e as interações que esse encontro proporciona.

Entre os autores que estudam o tema comensalidade destacam-se Flandrin e Montanari (1998) que a citam como um elemento "fundador" da civilização humana, que difere o homem civilizado dos outros animais. Considera que o homem civilizado além de comer para satisfazer uma necessidade física, também transforma essa "ocasião em um momento de sociabilidade, em um ato carregado de forte conteúdo social e de grande poder de comunicação" (FLANDRIN; MONTANARI, 1998, p. 108).

A relação entre a comensalidade e a sociabilidade presente neste artigo surge aliada ao interesse em investigar a hospitalidade em empreendimentos de alimentação em restaurantes comerciais supondo serem esses espaços de comensalidade e convivialidade, e um dos componentes da oferta turística. Também se justifica por contribuir à concepção de indicadores de hospitalidade "que permitam levantar dados relacionados à qualidade dos serviços de alimentação oferecidos aos turistas e à população residente" (ROCHA; AMARAL, 2012, p. 124).

Optou-se por estudar um caso centrado no Restaurante Madalosso, reconhecido por sua gastronomia e considerado também como uma atração turística. Situado no 
bairro Santa Felicidade, Curitiba (Paraná, Brasil), possui o título de "maior restaurante das Américas", com 4.645 lugares e área total de $7.671 \mathrm{~m}^{2}$, conforme reporta o portal do restaurante. Esse empreendimento faz parte do roteiro turístico do bairro Santa Felicidade e atende diversos perfis de clientes em um sistema de rodízio ${ }^{1}$ de massas e carnes.

De acordo com a Revista Alimentação Fora do Lar (2013), observa-se a expansão do setor de alimentos e bebidas, a partir da mudança do estilo de vida da população, em função da demanda por alimentação fora de casa, vindo a ser considerada como mais conveniente, saudável e prática. Bonin e Rolim (1991) ao analisarem o consumo alimentar contemporâneo verificaram uma série de mudanças sociais como a entrada da mulher no mercado de trabalho, o tempo reduzido para as refeições e o aumento do número de pessoas que moram sozinhas, determinando alterações nos hábitos alimentares e criando novas necessidades em torno da função alimentar. Borges (2011) explica que estes fatores resultaram na transformação dos hábitos alimentares favorecendo a busca por alternativas que subsistam as interações sociais em família ou grupo de pares nos momentos de alimentação.

Nesse contexto formulou-se a seguinte questão: Como a hospitalidade se apresentaria em um empreendimento comercial, do segmento de alimentação fora do lar, voltado para a gastronomia italiana e tido como atração turística e de lazer da cidade de Curitiba (PR)?

A partir desta problemática estabeleceu-se como objetivo primário verificar a importância da hospitalidade compreendida como um diferencial no Restaurante Madalosso, fundamentada na formação de uma identidade gastronômica, transformando-o em atração turística na visão dos seus proprietários gestores e clientes. Por objetivos secundários tem-se: a) contextualizar o processo imigratório italiano e sua culinária no bairro Santa Felicidade, situado na cidade de Curitiba-PR; b) caracterizar a evolução do empreendimento e a prestação de serviços aos clientes; e c) analisar a hospitalidade em suas diversas dimensões e significados no restaurante.

Com base no levantamento e na análise da bibliografia selecionada sobre comensalidade, hospitalidade, gastronomia e imigração italiana, compôs-se o referencial teórico pautado em estudiosos das práticas alimentares e das relações sociais como

\footnotetext{
${ }^{1}$ Conjunto de pratos que são oferecidos aos comensais em sequência de maneira rotativa.
} 
Lashley e Morrison (2004), Camargo (2004), Boutaud (2011), Brillat-Savarin (1999), Grosselli (1989) e Balhana (1978), fundamentando a pesquisa empírica.

A pesquisa tem um caráter qualitativo e exploratório-descritivo para a melhor compreensão da hospitalidade em um ambiente público e comercial. Adotou-se como estratégia o estudo de caso único, conforme proposto por Yin (2005), tendo em vista que está centrada em um empreendimento específico com representatividade no contexto local, regional e nacional. A Hospitalidade foi investigada com base das dimensões observadas no estudo de Lashley, Morrison e Randall (2005), ou seja: ocasião, companhia, atmosfera, comida, serviço e ambiente.

Este artigo apresenta os principais resultados da pesquisa, a qual foi desenvolvida no decorrer de programa de pós-graduação stricto sensu em nível de mestrado (BÖER, 2014), iniciando pelos fundamentos teóricos sobre Hospitalidade, Comensalidade e Sociabilidade, relacionados em suas relações com a Gastronomia. Em seguida, se aborda a influência dos hábitos e costumes dos imigrantes italianos na formação do Bairro de Santa Felicidade (Curitiba, Paraná), que explicam o início e evolução do Restaurante Madalosso, então tratado em destaque.

\section{HOSPITALIDADE, COMENSALIDADE E SOCIABILIDADE}

A hospitalidade se fundamenta na interação entre pessoas, instituindo uma dinâmica de reciprocidade. Beneficia a construção e o revigoramento da sociabilidade por meio da criação, do fortalecimento e do estabelecimento das relações e vínculos sociais. Para Gotman (2001), o conceito de hospitalidade faz referência ao processo de agregar o outro à comunidade, sendo a inospitalidade o processo inverso. As transformações da hospitalidade são citadas em entrevista com Marie Raynal publicada na Revista Hospitalidade (RAYNAL, 2013, p. 146):

A hospitalidade doméstica, desde o início da modernidade, vem sendo paulatinamente substituída pela hospitalidade urbana e virtual, mas permanece como a matriz de qualquer forma de contato interpessoal. Esta é a hipótese de fundo sobre a qual a antropóloga Anne Gotman estabelece suas reflexões. Ela mostra, ainda, as transformações atuais nas relações entre anfitrião e hóspede, em sentido amplo, de todo aquele que acolhe alguém em qualquer tempo e espaço, em especial a flexibilização das leis da hospitalidade. Não desapareceram os rituais de hospitalidade, nem os códigos sobre as quais estes repousam; mudaram, simplesmente. 
Por outro lado, Lashley e Morrison (2004) indicam a necessidade de uma definição ampla, que permita a análise das atividades relacionadas com a hospitalidade nos domínios social, privado e comercial. Assim, definem cada um desses domínios. O contexto no qual o Restaurante Madalosso está inserido relaciona-se com a hospitalidade no âmbito do domínio comercial, pois se refere à oferta da hospitalidade como atividade econômica privada e pública.

Camargo (2004) descreve a hospitalidade de forma analítica, na qual se criam dois eixos de tempos-espaços para a delimitação do campo de estudo: a) eixo cultural: que relaciona ações abrangidas pela noção de hospitalidade; e b) eixo social: que se refere aos modelos de interação social e consequentes instâncias físico-ambientais abrangidas.

Percebe-se que a hospitalidade abrange questões muito amplas e associadas à prestação de serviços. Para Grinover (2007, p. 32), hospitalidade "é fundamentalmente o ato de acolher e prestar serviços a alguém que por qualquer motivo esteja fora de seu local de domicílio". Dessa maneira, qualquer pessoa que não está em seu domicílio, pode ser considerada "hóspede" nos lugares onde frequenta e consome serviços. Tal visão se alinha a esta pesquisa, uma vez que se são estudados os serviços de alimentos e bebidas prestados a clientes frequentadores de um restaurante comercial.

Por outro lado, retoma-se Camargo (2004), para quem a hospitalidade, modelo de prática cultural, significa recepcionar ou receber pessoas, hospedar, alimentar e entreter. No seu entendimento a comensalidade, o ato de se alimentar juntos, é uma forma de dar início a uma nova relação ou de manter uma já estabelecida.

Boutaud (2011) destaca o compartilhar à mesa ou uma refeição com alguém, pois essa é uma das formas mais conhecidas de hospitalidade em qualquer época e cultura. Comer junto assume, portanto, um significado de ritual e de simbólico superior à simples satisfação de uma necessidade alimentar. Para ele, esta forma de partilha, de troca e de reconhecimento é chamada comensalidade e que está relacionada ao termo comensal, o ser que come com outro(s) ${ }^{2}$.

\footnotetext{
${ }^{2}$ O termo mangeur (comedor) apareceu na publicação Le Mangeur Du 19éme, de Jean Paul Aron em 1976, e foi reiterada em seminário de 1998, no sentido de distingui-lo do termo comensal (POULIN, 2004). Para Proença e Poulain (2006), o comedor é movido por motivos que lhe escapam como um ser biológico, um ser passional e um ser cultural; se refere, no contexto da sociologia da alimentação, ao ser que come, ao contrário do comensal, que significa o ser que come com outro ou com outros (POULIN, 2004, p. 20).
} 
Ao mesmo tempo em que a refeição satisfaz uma necessidade humana essencial, percebe-se que ela também é uma maneira de reforçar as relações sociais, a convivialidade e sociabilidade ou, inclusive, uma experiência, como explica Moreira (2010):

Comensalidade deriva do latim "mensa" que significa conviver à mesa e isto envolve não somente o padrão alimentar ou o quê se come mas, principalmente, como se come. Assim, a comensalidade deixou de ser considerada como uma consequência de fenômenos biológicos ou ecológicos para tornar-se um dos fatores estruturantes da organização social. A alimentação revela a estrutura da vida cotidiana, do seu núcleo mais íntimo e mais compartilhado. A sociabilidade manifesta-se sempre na comida compartida. (MOREIRA, 2010, p. 1).

Boutaud (2011, p. 1220) afirma que "a comensalidade é [...] uma forma de celebração da mesa e do discurso à mesa, como expressão de um laço de convivência". Telfer (1996) afirma que é por meio da oferta e da recepção da comida que um vínculo de confiança, de interdependência, de amizade e de generosidade é criado entre o anfitrião e a visita. Franco (2001, p. 22) complementa ao citar que a refeição é "a ritualização da repartição de alimentos" e por isso tornou-se tão rica em símbolos.

$\mathrm{Na}$ mesa os ritos de sociabilidade são percebidos por meio da relação entre as pessoas, na base da comunicação verbal e não verbal, em que se encontram pessoas queridas ou detestadas, porém, o protocolo de recepção a ser seguido é único, um protocolo teatral. Predomina a hospitalidade ensaiada, um comportamento encenado pelos atores responsáveis pela acolhida e recepção, de forma que seja bem aceita e espetacular por parte do hóspede. Essa hospitalidade ensaiada que existe no rito da alimentação torna-se um ciclo entre os convivas, pois "quem é hóspede em uma cena converte-se em anfitrião em outra, e essa alternância de papéis prossegue sem fim" (CAMARGO, 2004, p. 16).

Isso acontece em diferentes espaços como nos estabelecimentos de alimentos e bebidas que são "espaços de lazer urbano e locais propícios para relacionamentos interpessoais, favoráveis à vivência da sociabilidade nas mais diversas formas" (GIMENES, 2004, p. 73). A própria alimentação não pode ser vista isoladamente, pois envolve diversos fatores, tangíveis ou intangíveis, que ocorrem conjuntamente em uma experiência. 
Os clientes contemporâneos não "buscam somente produtos ou serviços, mas sim experiências que proporcionem vivenciar emoções e experimentar sensações e situações que complementem sua vida cotidiana", conforme apontam Pine II e Gilmore (1999, p. 2). De Toni e Schlüter (2003) complementam citando o desafio de transformar uma experiência de serviços em algo memorável, pois o processo de formação da experiência ocorre de maneira dinâmica, em que os fatores sociais, ou externos ao consumidor, agem concomitantemente com os processos cognitivos, ou internos.

Em um restaurante comercial, os clientes consomem, além da comida, da bebida e dos serviços, outros elementos, tais como o ambiente e sua decoração, a atmosfera que dele emana, o entretenimento oferecido e as relações entre os convivas, e destes com os que os atendem. Gândara, Gimenez e Mascarenhas (2009) destacam a importância que as demandas emocionais possuem cada vez mais em relação às demandas racionais. Barbosa e Farias (2012, p. 445) também ressaltam esses aspectos ao afirmarem que os restaurantes precisam oferecer algo mais para "fazer com que seus clientes vivam experiências de consumo".

Com foco na hospitalidade como experiência emocional, destaca-se a pesquisa de Lashley, Morrison e Randall (2005) sobre uma refeição inesquecível envolvendo estudantes britânicos do curso de Hotelaria e Hospitalidade. Os estudantes fizeram uma redação sobre uma refeição inesquecível, a qual foi analisada sob a ótica de seis dimensões da hospitalidade: ocasião, companhia, atmosfera, comida, ambiente e atendimento.

A dimensão ocasião permite identificar o caráter da comemoração e de carga emocional, além de fornecer uma compreensão dos valores sociais contemporâneos. "Há uma expectativa social de que os eventos da vida sejam marcados de maneira a incluir algum tipo de refeição coletiva" (LASHLEY; MORRISON; RANDALL, 2005, p. 198).

A dimensão companhia permite identificar as relações interpessoais estabelecidas, pois as refeições atuam como um ponto de encontro entre comensais. "Entende-se que a composição do grupo reforça a importância da refeição como espaço social de desenvolvimento da sociabilidade" (PAULA; DENCKER, 2007, p. 45).

A dimensão atmosfera é definida como o tom, ou estado de espírito, transmitido pelo lugar. Os componentes podem ser a decoração interior, a refeição festiva e o 
atendimento, sendo certo que a interpretação dada pelo participante a esses itens reflete sua experiência de socialização. Uma característica significativa na atmosfera é a sensação de estar "em casa", como as conotações de espaços: calorosos, simples, acolhedores, tradicionais e amistosos (LASHLEY; MORRISON; RANDALL, 2005).

Para a dimensão comida, podem-se identificar experiências inesquecíveis em refeições mais complexas e ao escolher alimentos ou estabelecimentos com expectativa cultural (de origem estrangeira). No entanto, a refeição também remete ao ambiente familiar ou à casa e dos amigos, uma ligação entre indivíduos e momentos do passado, entre gerações (LASHLEY; MORRISON; RANDALL, 2005).

A dimensão ambiente permite entender a percepção do cliente quanto ao espaço físico e sua familiaridade com o local. Nesse sentido, observa-se a relevância da hospitalidade doméstica para implicações comerciais. (LASHLEY; MORRISON; RANDALL, 2005).

A dimensão atendimento permite identificar a qualidade da prestação de serviços, estando implícitas as práticas de hospitalidade. "São as habilidades sutis, descritas como delicadeza, atenção aos detalhes e desejo de servir" (LASHLEY; MORRISON; RANDALL, 2005, p. 207).

Entre os resultados obtidos pelos autores, destaca-se, no âmbito deste artigo, o envolvimento emocional entre aqueles que recebem e os que são recebidos, mesclando a administração das emoções.

\section{GASTRONOMIA E IMIGRAÇÃO ITALIANA EM SANTA FELICIDADE}

Ao observar a culinária dos imigrantes da cidade de Curitiba-PR e, em especial, do bairro Santa Felicidade, Balhana (1958) relata que verificou em seus estudos que o alimento mais usual era a polenta: um prato característico das classes rurais italianas. Para a autora, nos traços característicos de determinada sociedade se destacam aqueles referentes à alimentação. A tradição alimentar é persistente e está menos sujeita às mudanças do que outras manifestações da vida material. Beluzzo (2006) salienta que:

Dentre as diferentes formas de memória coletiva, uma das mais persistentes é a memória culinária, com sua variedade de sabores, aromas e cores que 
resistem ao impacto do tempo e até mesmo desenraizamento cultural e geográfico. Por isso, a lembrança dos pratos feitos pelos antepassados ocupa um lugar tão importante nos relatos dos imigrantes, obrigados a se adaptarem a novas relações sociais, novos costumes e, sobretudo, novos hábitos alimentares, quando trocam de país (BELUZZO, 2006, p. 5).

Ainda assim, Balhana (1978) considera que durante o processo emigratório para a América os vênetos não encontraram dificuldade em manter a polenta na sua tradição alimentar, especialmente onde não havia a tradição do cultivo do trigo, como foi em terras brasileiras. A autora considerou que, em Santa Felicidade, a tradição e a influência do meio atuaram para a manutenção do regime alimentar (pelo menos em parte) a que os colonos estavam habituados em seu país de origem.

Em seus estudos Balhana (1958) descreve o comportamento dos emigrantes italianos no bairro Santa Felicidade com base na observação direta realizada no local. A autora relata que na alimentação cotidiana observou-se a utilização da polenta, do pão, das carnes e das gorduras, do leite e dos laticínios e do vinho, sendo que em Santa Felicidade destacava-se a polenta, prato característico das classes rurais italianas.

De acordo com Kluge (1996), inicialmente os restaurantes de Santa Felicidade surgiram funcionando de forma improvisada nas salas das casas dos colonos italianos. A comida tinha de ser encomendada com dias de antecedência, pois o bairro ficava longe do centro da cidade, não havia ônibus e o acesso por automóvel era difícil.

De acordo com essa mesma autora, os primeiros restaurantes - Iguaçu e Cascatinha - surgiram ao final da década de 1940. Na década de 1960 surgiram outros restaurantes e com o sucesso dessas iniciativas seguiram-se outras, dando início à transformação de Santa Felicidade em um bairro gastronômico. Um desses empreendimentos que se destacou e marcou o desenvolvimento do bairro foi $\mathrm{o}$ Restaurante Madalosso, criado em 1963.

Esse restaurante encontrou na tradição italiana um estilo de servir, e, em entrevista com Dona Flora Madalosso, uma das proprietárias do estabelecimento, mantém as suas origens, cuidando de cada cliente como um convidado, um velho amigo da casa. Possui 4.645 lugares distribuídos em nove salões que receberam denominações referentes às cidades italianas (Verona, Firenze, Bellagio, Gênova, Capri, Milano, Roma, Nápoli e Torino). Tem uma área total de $7.671 \mathrm{~m}^{2}$, dos quais aproximadamente $1.800 \mathrm{~m}^{2}$ destinam-se à produção, e um amplo estacionamento para até 1.200 carros e 
100 ônibus. Emprega 280 pessoas, sendo 160 garçons e 70 cozinheiras, e serve cerca de 1.500 refeições por dia e 50 mil por mês. (SANTA FELICIDADE..., 2013).

O restaurante atende diversos perfis de clientes ao mesmo tempo - residentes de Curitiba, principalmente famílias, turistas e participantes de eventos/profissionais, além de visitantes individuais ou em grupos. Conforme Dona Flora Madalosso, uma das proprietárias do estabelecimento, mesmo durante os dias de semana possui um elevado fluxo de clientes. É importante ressaltar que se trata de uma empresa familiar que é administrada pelos membros da família Madalosso.

\section{HOSPITALIDADE NO RESTAURANTE MADALOSSO}

Adiante, a narrativa da metodologia utilizada para o estudo, assim como a importância da forma de acolhimento aos frequentadores do local e as avaliações/percepções por eles informadas/noticiadas.

\subsection{METODOLOGIA}

A pesquisa foi estruturada com base na estratégia de estudo de caso único conforme proposto por Yin (2005). Teve como objeto de análise o Restaurante Madalosso, um espaço público e local de comensalidade e convivialidade, selecionado com base nos seguintes critérios: a) estabelecimento comercial situado em uma capital brasileira; b) empreendimento especializado em cozinha típica ou temática; e c) restaurante reconhecido na gastronomia da região e considerado uma atração turística do destino. A coleta de dados foi feita a partir da observação direta e participante, de entrevistas semiabertas e da consulta a documentos impressos e sítios da internet.

Para o estudo do restaurante, inicialmente foram consultados seu sítio oficial e alguns sítios eletrônicos de avaliação da qualidade de empreendimentos turísticos. $\mathrm{Na}$ primeira visita à Curitiba, foi consultado o acervo da biblioteca da Universidade Federal do Paraná e realizados contatos com pesquisadores desta universidade, além de busca de informações sobre o bairro em sítios turísticos e gastronômicos da internet, e visita ao restaurante, para observação e contatos iniciais com os proprietários e administradores, solicitando-se autorização para a realização da pesquisa. 
Nas visitas subsequentes, aprofundou-se a observação participante no bairro e no restaurante e foram aplicadas entrevistas iniciais, semiestruturadas, para aproximação do objeto de estudo com os seguintes grupos de sujeitos: a) três residentes do bairro Santa Felicidade que circulavam próximo ao restaurante; b) três proprietários ou gestores do restaurante; c) quatro profissionais da área de turismo e afins (guias de turismo e motoristas de ônibus de turismo) que acompanhavam grupos de turistas ao restaurante; d) três funcionários do serviço de sala do restaurante; e e) três clientes do restaurante - residentes de Curitiba e região (representantes de indivíduos, de grupos de amigos e de famílias) e turistas (nacionais e internacionais). Também foram visitadas agências de turismo receptivo na cidade de Curitiba e coletadas informações sobre atrações turístico-gastronômicas, em especial no bairro Santa Felicidade.

Ultrapassando esta etapa, os instrumentos foram revisados e as entrevistas finais foram aplicadas aos clientes. Estas foram gravadas, e posteriormente, transcritas, eliminando as pausas, interjeições, hesitações ou outros aspectos da comunicação oral. Foram entrevistadas trinta pessoas escolhidas aleatoriamente, situadas em mesas e salões distintos, entre famílias, amigos, turistas e profissionais, que concordaram em ser entrevistadas após terminarem a refeição.

A entrevista dirigida aos clientes foi estruturada em três blocos. No primeiro, perguntou-se aos respondentes: a) faixa etária; b) escolaridade; c) profissão e área de atuação; d) frequência ao restaurante; d) local de residência; e e) tipo de cliente, conforme especificado no parágrafo anterior. No segundo bloco, os dados coletados referiram-se à percepção do respondente sobre a hospitalidade no restaurante, mediante as seguintes categorias extraídas das dimensões observadas em estudo de Lashley, Morrison e Randall (2005): ocasião, companhia, atmosfera, comida, serviço e ambiente. No último bloco, pesquisaram-se: o envolvimento do respondente com o estabelecimento, o motivo pelo qual o estava frequentando e seus pontos fortes e fracos, em sua ótica.

\subsection{DIMENSÕES DA HOSPITALIDADE}

No decorrer das visitas realizadas ao restaurante em 2013 foram evidenciados o atendimento e os aspectos da hospitalidade. Observou-se a atuação e o desempenho dos 
profissionais que atendiam os clientes na recepção e no salão, em especial, os garçons. Estes demonstraram sentimento de familiaridade, ausência de cerimônia e pouco formalismo, mas centrados nas regras de um ritual de atendimento da área de alimentos e bebidas.

Tais fatos indicaram uma boa organização e competência na prestação de serviços aos clientes, considerando a dimensão do espaço físico e seus processos operacionais. Ao mesmo tempo, observou-se certa pressão aos clientes que, terminada a refeição, demoravam em encerrar a conta e liberar a mesa, sendo explicado pelo grande fluxo que impõe a alta rotatividade na ocupação das mesas.

Quanto à percepção acerca da hospitalidade foram selecionados os termos relacionados a cada uma delas, considerando a experiência dos clientes no Restaurante Madalosso (LASHLEY; MORRISON; RANDALL, 2005).

Em relação à dimensão ocasião, observou-se entre os respondentes a presença de grupos em encontros familiares, reunião com amigos, aniversários, reuniões de negócios, confraternizações de final de ano e visitas ao local em decorrência do turismo e do fluxo local. De um total de 30 termos citados, a concentração ocorreu nas ocasiões lazer (9) e turismo (7), seguidas de reuniões familiares e festivas, o que se considerou indicar ser o restaurante uma atração turística e de lazer.

Reforça-se que o ato de comer não se restringe à questão do alimentar em si, mas representa importantes funções simbólicas e sociais, já que a comensalidade permeia todas as relações sociais e possui dimensões culturais. Conforme Flandrin e Montanari (1998, p. 108), a alimentação não se faz apenas em razão da fome, mas também "para o encontro social a propiciar o convívio e comunicação entre os indivíduos". Desse modo, o encontro para a refeição, a par da simples provisão do corpo, propicia o desenvolvimento da convivência e identidade cultural de diversos grupos, como maneira de convivialidade e sociabilidade.

Percebeu-se que a subcategoria "lazer" precisa ser aprofundada em estudo futuro, pois pode estar integrada às demais. De outro lado, as ocasiões festas, confraternizações (entre amigos ou colegas de trabalho) e aniversário poderiam ser classificadas apenas como eventos festivos e comemorativos.

$\mathrm{Na}$ dimensão companhia, percebeu-se que a composição dos grupos reforça a importância da refeição como espaço que desenvolve a sociabilidade. Verificou-se que 
todos os entrevistados estavam acompanhados por familiares e/ou amigos, sendo que alguns destes eram amigos de trabalho. Dos 25 termos citados, a maior concentração ocorreu com a companhia de familiares.

No mesmo sentido, Paula e Denker (2007) anotam que a variável companhia permite comprovar, além do caráter da reunião, tipos de comportamento referentes ao hábito da refeição, seja solitária, seja em grupo. Portanto, tem-se que a composição do grupo reforça a importância da refeição como um espaço social de desenvolvimento da sociabilidade.

Na dimensão atmosfera, observou-se o tom ou estado de espírito transmitido pelo local, sendo que os entrevistados caracterizaram esta dimensão por meio de 54 termos, com destaque para acolhedora (13) e informal (12), além de calorosa (7), amistosa (6) e formal (5).

Cita-se um depoimento sobre a atmosfera acolhedora, associada a vínculos sociais de amizade: Acolhedor; se sente em casa, conhece todo mundo. Quem vem se identifica com um ou outro garçom e fica amigo. Com relação a este depoimento, podese destacar o conceito de hospitalidade atribuído por Grinover (2007), que destaca a hospitalidade como "o ato de acolher e prestar serviços a alguém que por qualquer motivo esteja fora de seu local de domicílio".

Observou-se ainda que a maioria das citações sobre a atmosfera do restaurante recaiu na palavra formal que também estava associada à palavra informal (4), ou seja, passa-se a hospitalidade encenada para a genuína em alguns momentos (CAMARGO, 2004 p. 83). Algumas palavras, embora pouco citadas, também traduziram a atmosfera como aconchegante, despojada, familiar, livre e receptiva.

$\mathrm{Na}$ dimensão ambiente, a percepção dos entrevistados quanto ao espaço físico revelou 50 termos, sendo que somente um entrevistado fez uma declaração negativa sobre a acústica ser ruim, que a tornou numericamente irrelevante no total das respostas. Todos os demais termos citados indicaram aspectos positivos do ambiente, qualificando-o com uma grande variedade de termos, principalmente familiar, acolhedor ou aconchegante (13) e grande ou espaçoso (12). Chamou atenção a citação de um entrevistado de sentir-se bem e de ser um local de apreciação (das pessoas, da decoração ou da comida). 
Considerando que o ambiente se associa ou se integra à atmosfera, lembra-se o pensamento de Wood (2005), de que o conhecimento holístico na alimentação é fruto de diversos elementos tangíveis e intangíveis, a interferir de maneira decisiva na escolha do local, da companhia para a refeição e do cardápio adequado. Gimenes (2003) reforça esse pensamento, ao afirmar que na sociedade atual a visita a um restaurante não busca apenas o consumo de comidas e bebidas, mas está permeada, sobremaneira, da atmosfera, grau de diversão e sociabilidade.

Com foco na dimensão comida, foram citados 50 termos, sendo que a maioria (44) indicou aspectos positivos da experiência no restaurante. Os aspectos negativos citados (6) apontaram para a falta de opções e a qualidade da comida entre média, fraca e ruim, com pouca significância perante a totalidade das respostas.

A refeição remete ao ambiente familiar, da casa, da mãe ou da avó, em lembranças do passado, como na infância, e a tradição culinária italiana (tipo de pratos em muita quantidade). Tendo em vista a refeição como ligação entre gerações, citam-se dois depoimentos que ilustram essas percepções: Boa. Remete a comida da mãe e avó (frango prensado, frango prensado e polenta); Maravilhosa. Se sente comendo na Itália. Lembra a comida da mãe e da avó).

A esse respeito, Pieper e Fremming (2013) destacam que o valor cultural de uma refeição representa um ato patrimonial, porquanto a comida é tradutora de povos, nações, civilizações, grupos étnicos, comunidades, famílias e indivíduos. Para Teixeira e Silva (2013), a atitude do comer com outras pessoas à mesa é uma necessidade que vai além do âmbito da sobrevivência da espécie. Constitui a sobrevivência da pessoa enquanto ser relacional, isto é, aquilo que se configura como uma necessidade social.

$\mathrm{Na}$ dimensão serviço, verificou-se um total de 33 termos, a maioria dos quais indicou aspectos positivos (29). Poucos foram os aspectos negativos citados (4): regular e ruim, massificado, agitado e barulhento (o que pode ser do ambiente e não do serviço). Assim, como na dimensão comida, os aspectos negativos tiveram pouca representatividade.

Os serviços foram percebidos de excelente a bom (23), associados ou não aos seguintes termos: atencioso, cordial, eficiente, maravilhoso e rápido (4). Considerou-se que isto indicou claramente aspectos da hospitalidade no bem receber e alimentar, com 
qualidade no atendimento aos clientes. Inclusive, um dos entrevistados citou que "os garçons fazem você se sentir em casa".

Verificaram-se, ainda, assertivas negativas sobre a percepção dos serviços 4), tais como: a) Eu acho meio massificado; b) Por ser um restaurante muito grande, talvez você não tenha um atendimento tão personalizado; c) Quando a gente chegou, chegou muita gente ao mesmo tempo. E, então, foi bem complicado o atendimento. Novamente aparecem os aspectos inerentes da hospitalidade no bem receber e alimentar que caracterizam a qualidade no atendimento.

Lembra-se aqui da afirmação de Cruz (2012) de que a qualidade oferecida em uma experiência gastronômica não é, de forma alguma, demasiada, uma vez que é uma importante garantia da sobrevivência e do sucesso desses empreendimentos.

\subsection{AVALIAÇÃO GERAL E COMO LUGAR HOSPITALEIRO}

Outros aspectos questionados aos entrevistados referiram-se aos pontos fortes e fracos do restaurante e à percepção do restaurante como um lugar hospitaleiro.

Quanto aos pontos fortes citados pelos entrevistados (30), verificou-se que o restaurante se destacou pela comida (15) em primeiro lugar, seguida pelo atendimento (8) e pelo ambiente (7). Em seguida, apareceram a rapidez, o espaço e o preço, e por fim, 23 pontos fortes, sendo que dois deles remeteram ao reconhecimento do restaurante como o "Maior da América", o "Destaque de Santa Felicidade" e que oferece as "Melhores massas do mundo".

De outro lado, julgou-se ser interessante a citação do café e do vinho, associados a outros pontos, como aspectos positivos. Algumas manifestações sobre a comida, o ambiente e o atendimento indicaram essa percepção positiva: a) Comida é excelente $e$ remete a uma comida feita em casa mesmo; b) Serviço supercordial, atencioso. Não faltou nada; c) Um lugar que está sempre muito cheio, muito animado. É ótimo.

Em relação aos pontos fracos, a metade dos entrevistados (15) disseram que o restaurante não apresentava aspectos fracos ou negativos. Dos 19 aspectos citados como negativos, destacou-se o cardápio (5) que poderia ter outras opções ou ser modificado, além de faltar explicação do sistema de rodízio. 
Outros pontos fracos citados foram: o volume de pessoas (3), a acústica (2) e o sabor da comida (2). Além desses, sete termos indicaram aspectos negativos pontuais relativos ao ambiente, serviço, preço e comida. Alguns entrevistados criticaram a falta de variação do cardápio e reclamaram do volume de pessoas no restaurante, conforme os seguintes comentários: a) É sempre a mesma mesmice; b) Poderia haver um pouquinho mais de, sei lá, uma segunda opção, pois é sempre a mesma coisa; c) Pela quantidade de pessoas deixa de ser algo mais reservado.

Por fim, com relação ao fato de o Restaurante Madalosso ser um lugar hospitaleiro, verificou-se que a maioria dos entrevistados (27) assim o considerou. O Quadro 1 apresenta trechos dos depoimentos que indicaram a criação e manutenção de vínculos sociais nas diversas dimensões da hospitalidade.

\section{QUADRO 1 - RESTAURANTE MADALOSSO COMO LUGAR HOSPITALEIRO}

\begin{tabular}{|c|c|c|}
\hline $\begin{array}{c}\text { LOCAL } \\
\text { HOSPITALEIRO }\end{array}$ & JUSTIFICATIVA & DIMENSÃO \\
\hline Sim & $\begin{array}{l}\text { [...] o próprio visual quando se entra, é um visual acolhedor. Vê } \\
\text { bastante gente, bastante confraternização. O atendimento é muito } \\
\text { bom também. }\end{array}$ & $\begin{array}{c}\text { Ambiente } \\
\text { Atmosfera } \\
\text { Atendimento }\end{array}$ \\
\hline Sim & $\begin{array}{l}\text { [...] as pessoas que frequentam esse ambiente são pessoas [...] que } \\
\text { você se identifica. Então, isso traz algo assim de mais acolhedor e } \\
\text { de mais hospitaleiro. }\end{array}$ & $\begin{array}{c}\text { Atmosfera } \\
\text { Ambiente }\end{array}$ \\
\hline Sim & $\begin{array}{l}\text { Aconchegante. Poderia ser mais hospitaleiro, dar mais atenção, se } \\
\text { fosse menos pessoas, porque, como é muita gente, não tem como } \\
\text { dar mais atenção. [...]. Resumindo, eu gostei. }\end{array}$ & $\begin{array}{c}\text { Ambiente } \\
\text { Atendimento }\end{array}$ \\
\hline Sim & $\begin{array}{l}\text { Tinha um senhor que trabalhava aqui, [...] e a minha família } \\
\text { conhecia ele. Era ótimo vir aqui só para encontrar com ele [...]. } \\
\text { Adoro o lugar [...]. }\end{array}$ & $\begin{array}{l}\text { Atendimento } \\
\text { Serviço } \\
\text { Ambiente } \\
\end{array}$ \\
\hline Sim & $\begin{array}{l}\text { [...] na entrada, você é bem recebido para aguardar a mesa. O } \\
\text { pessoal que trouxe a gente na mesa também. O estacionamento é } \\
\text { legal. }\end{array}$ & $\begin{array}{c}\text { Ambiente } \\
\text { Atendimento }\end{array}$ \\
\hline Sim & $\begin{array}{l}\text { [...] a partir do momento que ao entrar no restaurante você já } \\
\text { sente assim a comodidade e a receptividade das pessoas. Ao } \\
\text { estacionar e entrar pela portaria, já somos recebidos com uma } \\
\text { cordialidade, com sorriso de todo mundo [...]. E também aquela } \\
\text { tradição da família italiana, que está todo mundo [...] sempre } \\
\text { sorrindo de braços abertos. }\end{array}$ & $\begin{array}{l}\text { Atendimento } \\
\text { Atmosfera } \\
\text { Ambiente } \\
\text { Serviço }\end{array}$ \\
\hline Sim & $\begin{array}{l}\text { [...] eles pensaram bastante na questão de você ficar esperando. } \\
\text { Tem café, [...] batidas, água. Aí, eles te trazem aqui. Vem um rapaz } \\
\text { explicar a história da casa [...]. Aqui conta a história da D. Flora, } \\
\text { [...]. e ela está ali na cozinha. Os rapazes que vieram aqui, viram } \\
\text { que a gente gostou de tal coisa, aí vem trazer. Eu achei bem } \\
\text { simpático. }\end{array}$ & $\begin{array}{l}\text { Atendimento } \\
\text { Atmosfera } \\
\text { Ambiente } \\
\text { Serviço }\end{array}$ \\
\hline
\end{tabular}

Continua... 


\begin{tabular}{|c|c|c|}
\hline Sim & $\begin{array}{l}\text { [...] o lugar para as crianças brincarem. [...]. Então, eles comem e } \\
\text { já querem fazer alguma coisa, tanto que a gente está aqui fazendo } \\
\text { um pouco de tempo porque eles estão brincando. A qualidade da } \\
\text { comida é muito boa. Os garçons [...] você acaba tendo vontade de } \\
\text { comer aquilo que eles trazem, [e] a gente foi convidado a conhecer } \\
\text { a cozinha. }\end{array}$ & $\begin{array}{l}\text { Ambiente } \\
\text { Comida } \\
\text { Serviço }\end{array}$ \\
\hline Sim & $\begin{array}{l}\text { [...] o que você pedir eles atendem. Por exemplo, [...] eu não estou } \\
\text { boa, operei a coluna, estou com hérnia [...]: você me arranja uma } \\
\text { mesinha para mim? [...]. Eles dão um jeito, nem que não seja aqui } \\
\text { nesse salão, que seja em outro. Então é isso, essa hospitalidade } \\
\text { dela (D. Flora). }\end{array}$ & $\begin{array}{l}\text { Atendimento } \\
\text { Serviço }\end{array}$ \\
\hline Sim & $\begin{array}{l}\text { [...] remete uma coisa de família. Você vê muitas famílias e assim } \\
\text { eu não tenho do que reclamar. Então só pelo fato de eu não ter do } \\
\text { que reclamar eu já me sinto acolhida. }\end{array}$ & $\begin{array}{l}\text { Atmosfera } \\
\text { Ambiente }\end{array}$ \\
\hline Sim & $\begin{array}{l}\text { [...] toda a parte turística de Curitiba é sempre voltada para o } \\
\text { Madalosso, [...] eles atendem muito bem as excursões. }\end{array}$ & $\begin{array}{l}\text { Atendimento } \\
\text { Serviço }\end{array}$ \\
\hline Sim & $\begin{array}{l}\text { Veja o garçom sempre prestativo, não demora. Eles atendem } \\
\text { exatamente como se espera. [...] se você olhar em volta, é difícil ter } \\
\text { uma mesa de quatro pessoas. Só cheio de gente em volta assíduos } \\
\text { do restaurante. }\end{array}$ & $\begin{array}{l}\text { Atendimento } \\
\text { Serviço } \\
\text { Ambiente }\end{array}$ \\
\hline Sim & $\begin{array}{l}\text { Uma coisa que eu observo desde criança é a fidelidade que existe } \\
\text { de alguns funcionários [...]. Existe um garçom que nos atende aqui } \\
\text { sempre, [...] desde 1970. Quer dizer, já atendeu meu avô, já } \\
\text { atendeu meu pai, me atende. }\end{array}$ & Atmosfera \\
\hline Sim & [...] recebe muito bem, a atenção das pessoas. & \\
\hline Sim & $\begin{array}{l}\text { [...] minha esposa gosta muito da comida, principalmente porque } \\
\text { ela é de origem italiana. Já teve caso dela estar internada no } \\
\text { hospital e querer a comida daqui e eles liberaram [...]. Todas as } \\
\text { vezes que eu vim aqui fui muito bem atendido. [um dia destes] nós } \\
\text { combinamos aqui um evento [jantar], } 60 \text { pessoas. Por um lapso da } \\
\text { secretária, esta não informou para eles [...]. Nós viemos aqui e em } \\
\text { questão de dez minutos estava tudo resolvido [...]. Então é o } \\
\text { atendimento, a empatia. [...] Vinagre, por exemplo, eu estava } \\
\text { elogiando e ele foi lá e trouxe uma garrafinha para levar pra casa, } \\
\text { para temperar a salada da gente. Sem pedir. Então, essas coisas } \\
\text { que fazem com que você se sinta bem. }\end{array}$ & $\begin{array}{l}\text { Ambiente } \\
\text { Serviço } \\
\text { Atendimento }\end{array}$ \\
\hline Sim & $\begin{array}{l}\text { A quantidade de gente que eles atendem ao mesmo tempo é } \\
\text { espetacular. }\end{array}$ & Serviço \\
\hline Sim & [...] da receptividade dos funcionários. & Atendimento \\
\hline Sim & $\begin{array}{l}\text { [...] a recepcionista supergentil, superatenciosa. Os garçons } \\
\text { também superatenciosos. Não é aquela coisa robótica. }\end{array}$ & $\begin{array}{l}\text { Atendimento } \\
\text { Serviço }\end{array}$ \\
\hline Sim & $\begin{array}{l}\text { [...] por todo o conjunto: a receptividade, a qualidade, a comida, o } \\
\text { preço. }\end{array}$ & $\begin{array}{l}\text { Atendimento } \\
\text { Serviço } \\
\text { Comida }\end{array}$ \\
\hline Sim & {$[\ldots]$ um lugar assim bem familiar [...]. } & Atmosfera \\
\hline Sim & $\begin{array}{l}\text { [...] a gente está muito bem recebido. Apesar de ser grande a gente st } \\
\text { sente acolhido. } O \text { atendimento é rápido. }\end{array}$ & $\begin{array}{l}\text { Atendimento } \\
\text { Serviço }\end{array}$ \\
\hline Sim & [...] é família. & Atmosfera \\
\hline Sim & $\begin{array}{l}\text { [...] é agradável. Você se sente em casa mesmo com o tamanho } \\
\text { deste restaurante [...] o ambiente bom, [...] aspecto da comida } \\
\text { italiana e o jeito das pessoas tratarem a nós clientes. }\end{array}$ & $\begin{array}{l}\text { Atendimento } \\
\text { Atmosfera } \\
\text { Ambiente }\end{array}$ \\
\hline Sim & $\begin{array}{l}\text { [...] recebe bem, bem educados, delicados. Por isso eu acho que } \\
\text { sim. }\end{array}$ & Serviço \\
\hline
\end{tabular}

Continua... 
Continuação.

\begin{tabular}{|c|c|c|}
\hline Sim & $\begin{array}{l}\text { [...] o estacionamento bom, apesar de estar sempre lotado, [...] um } \\
\text { belo cafezinho, se você quer comprar um bom vinho, se quiser } \\
\text { comprar um vinagre de qualidade, estas coisas que me chamam, } \\
\text { me acolhe. }\end{array}$ & $\begin{array}{c}\text { Ambiente } \\
\text { Atendimento }\end{array}$ \\
\hline Sim & $\begin{array}{l}\text { [...] é como minha casa. Todos são meus amigos aqui. Você está } \\
\text { vendo este pacotinho aqui? Isso é polenta que o garçom separa } \\
\text { para eu levar para casa, isso sem eu pedir. Eles sabem tudo o que } \\
\text { eu gosto. Eles criam um ambiente formidável. É todo um conjunto } \\
\text { de coisas que fazem sentir bem recebido e diferenciado". }\end{array}$ & $\begin{array}{l}\text { Ambiente } \\
\text { Atmosfera } \\
\text { Atendimento } \\
\text { Serviço }\end{array}$ \\
\hline Não & $\begin{array}{l}\text { [...] ambiente com muita gente. Eles não conseguem personalizar o } \\
\text { atendimento; é tudo padrão, é tudo uma máquina. }\end{array}$ & $\begin{array}{l}\text { Atendimento } \\
\text { Serviço }\end{array}$ \\
\hline Não & $\begin{array}{l}\text { [...] pela escala de atendimento. } O \text { atendimento é de uma multidão, } \\
\text { por isso nem pode ser totalmente acolhedor. }\end{array}$ & Atendimento \\
\hline Não & $\begin{array}{l}\text { É bom a gente conhecer. Hoje foi uma casualidade. A gente tem } \\
\text { aqui em Santa Felicidade outros que eu curto mais. }\end{array}$ & \\
\hline
\end{tabular}

FONTE: Pesquisa de campo, 2015.

Ficou reforçada nos depoimentos a sensação de estar em uma grande família composta pelos familiares ou amigos, aos quais se somavam outros frequentadores e os amigos da casa (profissionais do restaurante), levando-os a sentir um ambiente como extensão da própria casa da família. Nesse sentido, esses frequentadores manifestaram sentir-se parte da família Madalosso, parte do próprio restaurante, mesmo em um local espaçoso (enorme) e lotado.

$\mathrm{Na}$ ótica dos entrevistados, o restaurante foi hospitaleiro, principalmente, em relação ao ambiente, à atmosfera e ao serviço. No entanto, também houve referência à ocasião, à companhia e à comida. Tais resultados confirmaram a adequação das dimensões da hospitalidade propostas por Lashley, Morrison e Randall (2005) não apenas para refeições inesquecíveis, mas também para restaurantes "memoráveis".

\section{CONSIDERAÇÕES FINAIS}

Nesta pesquisa se investigou como a hospitalidade se apresentava em um empreendimento público e comercial do segmento de alimentação fora do lar, de gastronomia italiana e reconhecido como atração turística e de lazer da cidade de Curitiba, no estado do Paraná (Brasil). A escolha do restaurante Madalosso foi considerada pertinente por reforçar a importância do estudo da hospitalidade e sua relação com a comensalidade e a sociabilidade. 
A pesquisa de campo trouxe resultados que demonstraram a identidade do empreendimento e suas características gerais explicativas do seu posicionamento no turismo e lazer curitibanos. Constatou-se na gastronomia a primazia das produções, principalmente nos quesitos sabor e qualidade em relação à proposta do restaurante de apresentar uma culinária caseira italiana.

Pela atuação dos funcionários no seu salão, verificou-se o bom atendimento da equipe, elevando os sentimentos de familiaridade, ausência de cerimônia e formalismo, porém, com a utilização de regras e rituais, evidenciando o espaço público como um local de hospitalidade, comensalidade e convivialidade.

A experiência vivida pelos clientes no restaurante envolveu, de um lado, a própria refeição, e de outro, as suas formas de interação (dimensão companhia e ocasião) e a equipe de funcionários. Assim, não apenas a qualidade dos alimentos (dimensão comida) e o atendimento (dimensão serviço) são importantes, como também o bem-estar dos clientes (dimensões atmosfera e ambiente).

As percepções dos entrevistados quanto aos pontos fortes e fracos do restaurante reforçaram uma visão positiva, de um lugar hospitaleiro para os residentes e turistas. $\mathrm{O}$ comer no restaurante foi visto como uma atividade de lazer nos momentos do alimentar, conviver, conversar, relaxar e/ou entreter. Nele, a comensalidade se torna expressão maior da hospitalidade e todos se relacionando com os aspectos relativos ao atendimento, convívio, familiaridade e prazer associados a um ritual particular em que a espontaneidade e a qualidade da alimentação despontam como pilares. Nesse sentido, a herança da cultura italiana se traduz na comensalidade do restaurante em momentos de alegria, reunião familiar e comida saboreada associada a um ambiente acolhedor.

O prazer da alimentação se agrega ao da companhia, estar com os convivas à mesa ou com os funcionários e proprietários do restaurante. Tais encontros, em meio a um ritual de bom atendimento e qualidade da alimentação, favorecem as interações e apontam a criação de relações e vínculos sociais. Como resultado, aparece a amizade, o carinho e o respeito, que, no caso estudado, se integraram à familiaridade, ao ambiente familiar e ao de fazer parte da "família Madalosso", transformando até a espera do atendimento em aspecto positivo da comensalidade.

Os resultados obtidos possibilitaram a compreensão sobre a formação e identidade do objeto de estudo, a percepção das dimensões e os significados da 
hospitalidade no restaurante na visão dos seus gestores, colaboradores e clientes. A comensalidade aliada à convivialidade no estabelecimento é influenciada positivamente pela hospitalidade em todas as dimensões estudadas.

Para investigações futuras, percebeu-se as inúmeras possibilidades de aprofundar o estudo da hospitalidade em restaurantes comerciais. Uma delas é o tratamento de cada dimensão, em particular, testando e definindo os indicadores de análise para a maior compreensão da hospitalidade no âmbito da comensalidade em um contexto de turismo e de lazer.

\section{REFERÊNCIAS}

BALHANA, A. P. Santa Felicidade uma paróquia Vêneta no Brasil. Curitiba: Fundação Cultural de Curitiba, 1978.

. Santa Felicidade um processo de assimilação. Curitiba: Fundação Cultural de Curitiba, 1958.

BELUZZO, R. A valorização da cozinha regional. In: ARAUJO, W.; TENSER, C. (org.). Gastronomia: cortes \& recortes. Brasília: SENAC, 2006.

BOER, L. Hospitalidade no Restaurante Madalosso: comensalidade e sociabilidade. Dissertação (Mestrado em Hospitalidade) - Universidade Anhembi Morumbi, São Paulo, 2015.

BONIN, A.; ROLIM, M. C. M. B. Hábitos alimentares: tradição e inovação. Boletim de Antropologia, Curitiba, v. 4, n. 1, p. 75-90, jun. 1991.

BORGES, A. M. B. Análise da produção bibliográfica sobre comensalidade em família: os artigos levantados na base de dados ISI Web of Science (1990-2011). 2011. Dissertação (Mestrado em Hospitalidade) - Universidade Anhembi Morumbi, São Paulo, 2011.

BOUTAUD, J. J. Compartilhar a mesa. In: MONTANDON, A. (Org.). O livro da hospitalidade: acolhida do estrangeiro na história e nas culturas, São Paulo: Editora Senac, 2011, p. 1213-1230.

BRIllat-SAVARIN, J. A. A fisiologia do gosto. São Paulo: Cia das Letras, 1999.

CAMARGO, L. O. L. Hospitalidade. São Paulo: Aleph, 2004. 
CRUZ, R. A. Parâmetros de referência na prestação de serviços de atendimento no setor da restauração. Dissertação de Mestrado em Turismo e Hotelaria. Universidade do Vale do Itajaí. Balneário Camboriú, 2012.

DE TONI, D.; SCHÜLER, M. The strategic management of products images: a mensuration of wine images. In: ANNUAL CONFERENCE BALAS 2003 - Business Association of Latin American Studies, São Paulo, 2003.

GÂNDARA, J. M. G.; GIMENES, M. H. S. G.; MASCARENHAS, R. G. Reflexões sobre o turismo gastronômico na perspectiva da sociedade dos sonhos. In: PANOSSO NETTO, A.; ANSARAH, M. G. (Org.). Segmentação do mercado turístico - estudos, produtos e perspectivas. Barueri: Manole, 2009, p.179-194.

GIMENES, M. H. S. G. Lazer e prazer - O consumo simbólico e a vivência da sociabilidade em bares e casas noturnas no inicio do século XXI na cidade de Curitiba, Paraná. Dissertação de Mestrado: Universidade Federal do Paraná, 2003.

GIMENES, M. H. S. G. Bares e casas noturnas: um estudo exploratório sobre consumo e sociabilidade. Turismo em Análise, v. 15, n. 1, p. 73-88, 2004.

GOTMAN, A. Le sens de l'hospitalité: essai sur les fondements sociaux de l'accueil de l'autre. París: Presses Universitaires de France, 2001.

GRINOVER, L. A hospitalidade, a cidade e o turismo. São Paulo: Aleph, 2007.

FLANDRIN, J.; MONTANARI, M. A história da alimentação. 4. ed. São Paulo: Estação Liberdade, 1998.

FRANCO, A. De caçador a gourmet: uma história da gastronomia. 4. ed. São Paulo: SENAC, 2001.

GROSSELLI, R. D. Cresce l'araucaria dal primiero a novo Tirol. Contandini trentini (veneti e lombardi) nelle foreste brasiliane. Trento: Litografia EFFE/ERRE, 1989.

HUBNER, R. Entre quatro panelas: baseado na vida de Flora Madalosso Bertolli. Curitiba: Ricardo Antonio Hubner, 2007.

KLUGE, F. M. O Vêneto não pode morrer! Um estudo sobre restaurantes, rituais e (re)construção da identidade italiana em Santa Felicidade. Mestrado(Dissertação). Departamento de Antropologia, Universidade Federal do Paraná, Curitiba, 1996.

LASHLEY, C.; MORRISON, A. Em busca da hospitalidade: perspectiva para um mundo globalizado. Barueri: Manole, 2004. 
LASHLEY, C.; MORRISON, A.; RANDALL, S. Minha refeição inesquecível! A hospitalidade como experiência emocional. In: SLOAN, Donald (Org.). Gastronomia, restaurantes e comportamento do consumidor. Barueri: Manole, 2005. p. 191-214.

MOREIRA, S. A. Alimentação e comensalidade: aspectos históricos e antropológicos. São Paulo, v. 62, n. 4, out. 2010. Disponível em: <http://cienciaecultura .bvs.br/scielo.php?script=sci_arttext\&pid=S0009-67252010000400009>. Acesso em: $11 / 07 / 2013$.

PAULA, N. M.; DENCKER, A. F. M. Contribuição para a interpretação do consumo em restaurantes sob a perspectiva sociológica. Revista Brasileira de Gestão de Negócios, São Paulo, v. 9, n. 23, p. 42-50. Jan/abr. 2007.

PIEPER, G. W.; FREMMING, L. M. S. A valorização da gastronomia como atrativo turístico sustentado e desenvolvendo a FENADI - IJUI. In: TERNER, A. R.; KRAEMER, M. A. D. (Org.). Aportes do V Simpósio Iberoamericano em Comércio Internacional, Desenvolvimento e Integração Regional. Santa Rosa: FEMA, 2013, p. 94-103.

PINE II, B. J.; GILMORE, J. H. The experience economy: work is theatre \& every business a stage. Boston: Harvard Business School Press, 1999.

POULIN, J.P. Sociologias da alimentação. Os comedores e o espaço social alimentar. Florianópolis: Editora da UFSC. 2004.

RAYNAL, M. Entrevista com Anne Gotman. Revista Hospitalidade, São Paulo, v. 10, n. 1, p. 146-157, jun. 2013.

RESTAURANTE MADALOSSO. Disponível em: <http://www.madalosso.com.br:>. Acesso em: 08/07/2013.

REVISTA ALIMENTAÇÃO FORA DO LAR. Disponível em: <http://www.cozinhaprofissional.com.br/exibir.php?id=1436>. Acesso em: 26/12/2013.

ROCHA, F. G. R.; AMARAL, F. M. A. Qualificação para as atividades do turismo: Perfil profissional de trabalhadores, proprietários e gestores de empresas de alimentação fora do lar na Região Litorânea Central do Estado de Santa Catarina (Brasil). Turismo \& Sociedade, Curitiba, v. 5, n.1, p. 124-143, abr. 2012.

SANTA FELICIDADE, reduto gastronômico E COMILANÇA. Pizzas \& Massas, São Paulo, v. 1, n. 8, p. 48-53.

TEIXEIRA, C.; SILVA, A. W. C. A cultura da mesa de refeição e o seu aspecto teológico e religioso. Revista Eletrônica Espaço Teológico, v. 7, n. 11, jan./jun., 2013, p. 2-11. 
TELFER, E. Food for thought: philhosophy and food. London: Routledge, 1996.

WOOD, R. C. Dining out on social neglect. Britsh Food Journal, v. 96, n. 10, 1994.

YIN, R. K. Estudo de caso: planejamento e métodos. São Paulo: Bookman, 2005.

Recebido em: 01-02-2016.

Aprovado em: 02-03-2016. 